OPEN ACCESS

Edited by:

Kai Wang,

Chinese Academy of Agricultural Sciences (CAAS), China

Reviewed by:

Menglan Xiang,

Stanford University, United States

Xiao-Xuan Guo,

Chinese Academy of Agricultural Sciences (CAAS), China

Naama Geva-Zatorsky,

Technion Israel Institute of

Technology, Israel

${ }^{*}$ Correspondence:

Liuqin $\mathrm{He}$

285687180@qq.com

Jianzhong L

ljzhong@hunnu.edu.cn

Tiejun Li

tjil@isa.ac.cn

${ }^{\dagger}$ These authors have contributed equally to this work and share first authorship

Specialty section:

This article was submitted to Nutritional Immunology, a section of the journal Frontiers in Immunology

Received: 30 November 2020 Accepted: 22 January 2021

Published: 16 February 2021

Citation:

Long J, Guan P, Hu X, Yang L, He L,

Lin Q, Luo F, Li J, He X, Du Z and Li T

(2021) Natural Polyphenols as

Targeted Modulators in Colon Cancer:

Molecular Mechanisms and Applications.

Front. Immunol. 12:635484. doi: 10.3389/fimmu.2021.635484

\title{
Natural Polyphenols as Targeted Modulators in Colon Cancer: Molecular Mechanisms and Applications
}

\begin{abstract}
Jing Long 1,2†, Peng Guan ${ }^{1,2+}$, Xian Hu ${ }^{1,2}$, Lingyuan Yang ${ }^{3}$, Liuqin He ${ }^{1,2 *}$, Qinlu Lin ${ }^{4}$, Feijun $\mathrm{LuO}^{4}$, Jianzhong $\mathrm{Li}^{1 *}$, Xingguo $\mathrm{He}^{5}$, Zhiliang $\mathrm{Du}^{6}$ and Tiejun $\mathrm{Li}^{2 *}$

${ }^{1}$ Hunan Provincial Key Laboratory of Animal Intestinal Function and Regulation, Laboratory of Animal Nutrition and Human Health, College of Life Sciences, Hunan Normal University, Changsha, China, ${ }^{2}$ Key Laboratory of Agro-ecological Processes in Subtropical Region, Hunan Provincial Key Laboratory of Animal Nutritional Physiology and Metabolic Process, Institute of Subtropical Agriculture, Chinese Academy of Sciences, Changsha, China, ${ }^{3}$ College of Animal Science and Technology, Hunan Agricultural University, Changsha, China, ${ }^{4}$ National Engineering Laboratory for Deep Process of Rice and Byproducts, Hunan Key Laboratory of Grain-oil Deep Process and Quality Control, College of Food Science and Engineering, Central South University of Forestry and Technology, Changsha, China, ${ }^{5}$ Changsha Green Leaf Biotechnology Co., Ltd., Changsha, China, ${ }^{6}$ Cloud Computing Center, Chinese Academy of Sciences, Dongguan, China
\end{abstract}

Colon cancer commonly develops from long-term chronic inflammation in the intestine and seriously threatens human health. Natural polyphenols have been valued as a crucial regulator of nutrient metabolism and metabolic diseases, owing to their anti-inflammatory and antioxidant functions and the ability to maintain a balance between gut microbes and their hosts. Notably, experimental and clinical evidence has shown that natural polyphenols could act as a targeted modulator to play a key role in the prevention or treatment of colon cancer. Thus, in this review, we summarized recent advances in the possible regulatory mechanism and the potential application of natural polyphenols in colon cancer, which might be regarded as a novel platform for the colon cancer management.

Keywords: natural polyphenols, colon cancer, targeted modulator, inflammation, microbe

\section{INTRODUCTION}

Colon cancer is one of the most common malignant tumors, which seriously affects the health of modern people. With the change of people's living habits and diet, the incidence of colon cancer is increasing year by year. There are 1.1 million new cases and about 500,000 deaths worldwide every year (1), and the age of onset is younger (2). Colon cancer originates from chronic inflammatory sites or tumor stem cells. On the one hand, colon cancer may originate in a chronically inflamed area with an imperfect repair mechanism that causes normal cell mutations, metastases, and colonization in the colon, resulting in the development of cancer $(3,4)$. For example, some of genetic, pharmacological and epidemiological data showed that inflammatory bowel disease (IBD) increase risk of colon cancer (5). The development of colon cancer induced by IBD is thought to be multifaceted, with inflammation, injury, increased epithelial cell proliferation rate (6). Proactive measures should be taken to prevent the progression of IBD to colon cancer. 
On the other hand, recent studies have revealed that colorectal cancers are mainly originated from cancer stem cells or stem cell-like cells (7). The main pathogenesis of cancer stem cells is derived from the disorder of expression of genetic and epigenetic genes involved in inactivation of tumor suppressor genes and activation of oncogenes.

Traditional therapies, such as surgery, chemotherapy, and radiotherapy have great effects as cancer treatments, drug resistance and toxicities remain as major problems in the treatment of patients with cancer. Therefore, the best available and safest therapies are probably nutritional regulation, involving natural polyphenol products, functional amino acids, and numerous dietary treatments, which can help to improve the symptoms of colon cancer and the quality of life of the patients with colon cancer $(8,9)$. Ohno et al. demonstrated that curcumin could be considered as an effective therapy for treating IBD by improving the abundance of butyrate-producing bacteria and suppressing NF- $\kappa \mathrm{B}$ activation (10). Quercetin administration could upregulate the expression of tight junction proteins (i.e., $\mathrm{ZO}-1$, occludin), preventing damage to indomethin-induced Caco-2 cells (11). Many in vivo or in vitro experiments have also confirmed that polyphenols and polyphenol-rich whole foods are capable of elevating butyrate producers and probiotics, alleviating colitis (12). Therefore, in this review, we summarize the recent advances in the possible regulatory mechanism and potential application of natural polyphenols, which would be a juncture point of nutrition and medicine that holds considerable promise in treating colon cancer.

\section{TYPES AND METABOLISM OF POLYPHENOLS}

More than 8,000 natural polyphenol products have been found in the flowers, roots, leaves, and fruits of plants, which are considered as secondary metabolites and primarily exist as the benzene rings that bind to multiple hydroxyl groups or are sometimes linked to aromatic carbon (13). According to the different substituents on benzene rings, natural polyphenol products can be divided into flavonoids (i.e., flavones, flavonols, isoflavones, neoflavonoids, chalcones, and anthocyanidins) and non-flavonoids (i.e., phenolic acids, stilbenoids, and phenolic amides) (Table 1) (19). It has been reported that polyphenols are produced by the shikimate or acetate pathway and possess numerous positive functions, including anti-inflammatory and antioxidant effects, maintaining intestinal microecological balance, and inhibiting cell apoptosis (18, 20-23).

It is known that only $5-10 \%$ of polyphenols are absorbed in the intestine, while $90-95 \%$ of polyphenols are absorbed in other

Abbreviations: IBD, inflammatory bowel disease; SOD, superoxide dismutase; NADPH, nicotinamide adenine dinucleotide phosphate hydrogen; ROS, reactive oxygen species; AMPK, $5^{\prime}$ AMP-activated protein kinase; CRC, colorectal cancer; PTEN, tumor suppressor factor; PCNA, proliferating cell nuclear antigen; BMP7, bone morphogenetic protein; CDK7, cyclin-dependent kinase-7; HPLC-MS, high performance liquid chromatography-mass spectrometry; SCFAs, Short-chain fatty acids; MAPK, activated protein kinase; JNK, c-Jun N-terminal kinase; GSK-3 $\beta$, serine/threonine kinases; NO, nitric oxide; GAE, gallic acid equivalent; PPAR $\gamma$, peroxisome proliferator-activated receptor gamma.
TABLE 1 | The main sources of polyphenols in the diet.

\begin{tabular}{|c|c|}
\hline Items & Dietary sources \\
\hline \multicolumn{2}{|l|}{$\begin{array}{l}\text { Flavonoids } \\
(14-17)\end{array}$} \\
\hline Flavones & Onion, apple, cherry, broccoli, tomato \\
\hline Flavonols & $\begin{array}{l}\text { Fruits, vegetables, and beverages, beer, tea, cocoa, pulses, } \\
\text { spices }\end{array}$ \\
\hline Flavanones & Tomatoes, pulses, aromatic plants, aromatic plants \\
\hline Flavanols & $\begin{array}{l}\text { Tea, red wine, chocolate, skins of grape, skins of apple, } \\
\text { blueberry }\end{array}$ \\
\hline Isoflavonoids & soy, leguminous plants \\
\hline Anthocyanidins & Flower petals, fruits, vegetables, varieties of grains, black rice \\
\hline Proanthocyanidins & Berries, tea, wine, pommes, drupes, nuts, pulses \\
\hline \multicolumn{2}{|l|}{$\begin{array}{l}\text { Non-flavonoids } \\
(16,18)\end{array}$} \\
\hline Phenolic acids & $\begin{array}{l}\text { Wine, coffee, apple, cocoa, tea, vegetables, fruits spices, } \\
\text { aromatic plants }\end{array}$ \\
\hline Stilbenoids & Cocoa, red wine, peanuts, grapes, almonds \\
\hline
\end{tabular}

tissues, such as the liver, adipose, and skeletal muscle tissues (Figure 1). Gut microbes play a key role in the digestion and absorption of food polyphenols, especially in the metabolism of high molecular weight polyphenols into bioactive metabolites $(24,25)$. Once the polyphenols are transported to the colon, they can be hydrolyzed and metabolized by the colonic microflora to produce aromatic acids $(26,27)$. When polyphenols are degraded in the small intestine or colon, their metabolites enter the liver. From the liver, most of these metabolites are transported to all parts of the body through the portal vein and participate in various metabolic processes involved in methylation, glucuronidation, and sulfation (25). Additionally, some other metabolites are excreted in the form of bile components that are regenerated by intestinal microbial enzymes before reabsorption, and other unabsorbed metabolites are excreted in the feces (28).

\section{MOLECULAR MECHANISMS OF POLYPHENOLS IN COLON CANCER}

It is well-established that natural polyphenols have been reported as an important regulator of intestinal health, including maintaining intestinal nutrient transport and absorption, improving microorganism homeostasis, and promoting growth and development in animals and humans (Figure 2). Recently, an increasing number of studies have shown the regulatory mechanism of polyphenols in the prevention and treatment of colon cancer (29), the details of which are shown in Figure 3 and Table 2.

\section{Polyphenols as Efficient Regulators of Oxidative Stress}

Owing to the presence of active phenolic hydroxyl groups, polyphenols are considered to be efficient hydrogen donors, reducing agents, and metal chelators, which play an important role in antioxidant function. Some studies have shown that 


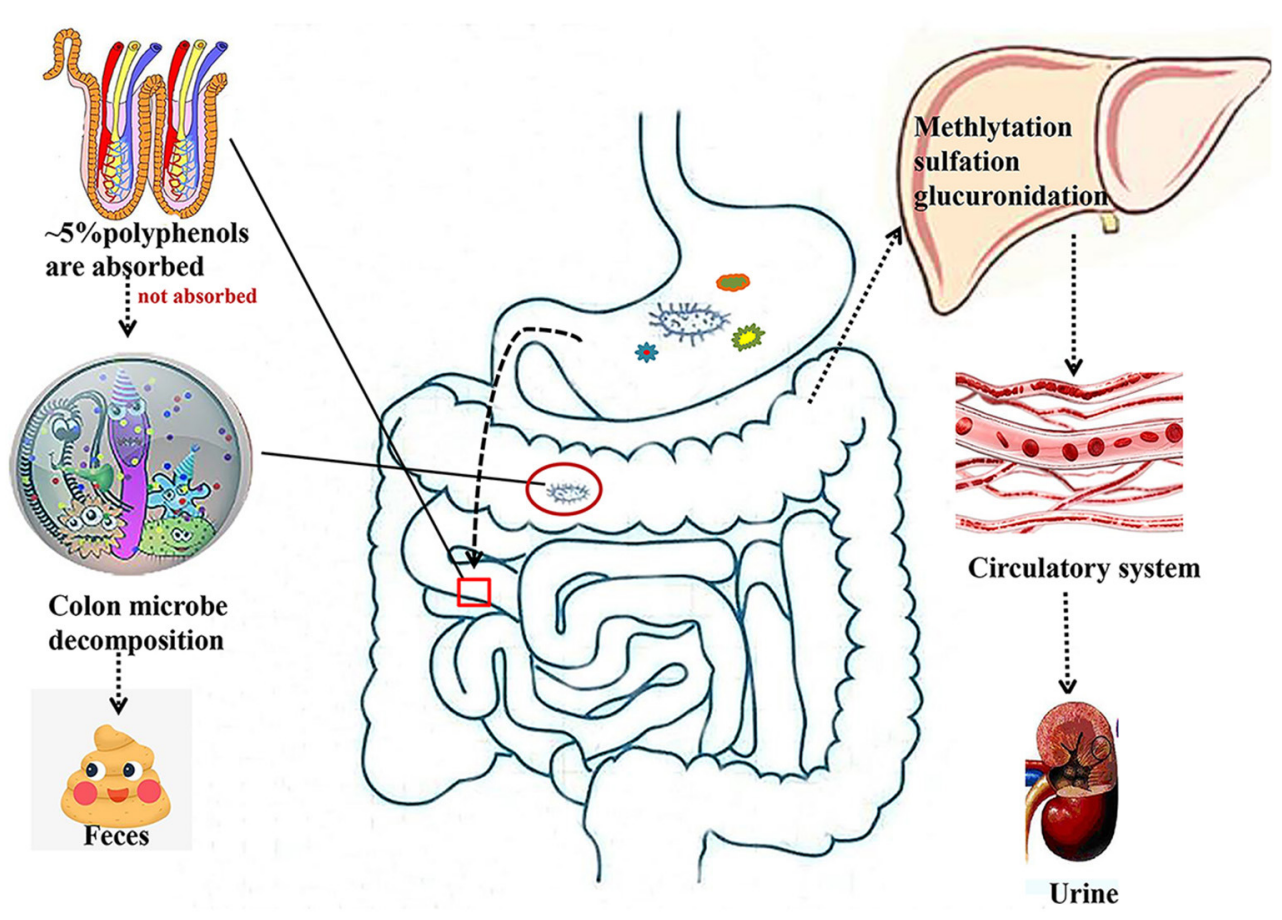

FIGURE 1 | Absorption and metabolism of natural polyphenols. Most polyphenols are metabolized by microorganisms in the colon into small molecules that enter the liver and then circulate through the bloodstream into the circulatory system.

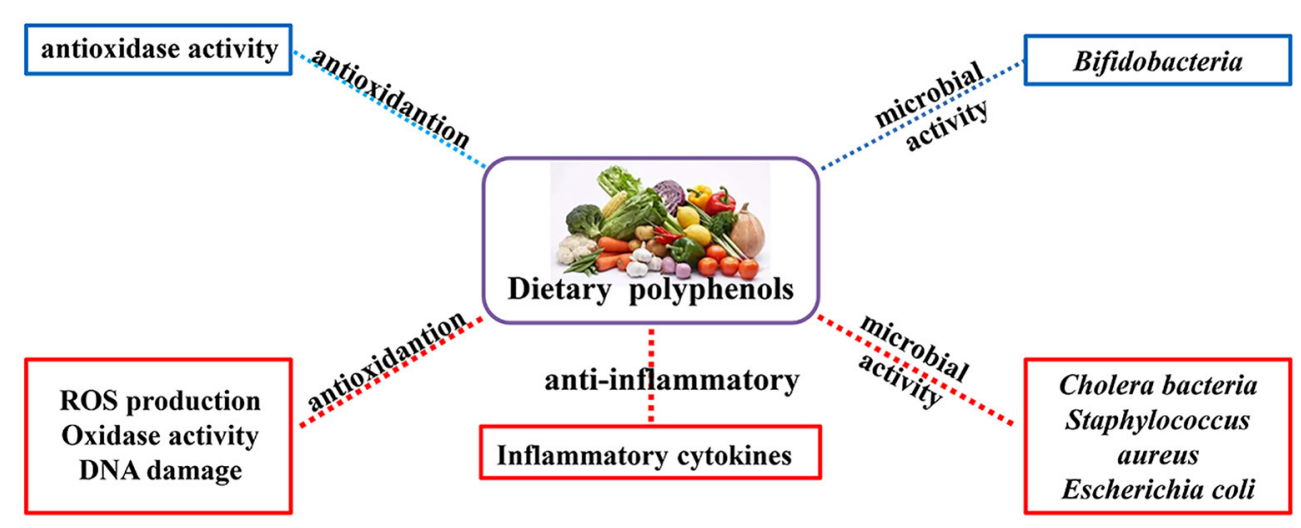

FIGURE 2 | Physiological and nutritional functions of natural polyphenols. The biological functions of polyphenols are mainly antioxidant, anti-inflammatory and regulation of intestinal microorganisms (Red indicates inhibition; blue indicates promotion).

polyphenols can form $\mathrm{Fe}^{3+}$ with $\mathrm{Fe}^{2+}$ because of the chelating potential of hydroxyl groups, and then inhibit the damage of $\mathrm{Fe}^{2+}$ to DNA (42). Other studies have demonstrated that polyphenols can inhibit the production of nicotinamide adenine dinucleotide phosphate hydrogen (NADPH) oxidase (NOX), thereby decreasing the production of $\mathrm{O}_{2}^{-}$in vascular endothelial cells (43). Additionally, polyphenols can reduce the synthesis of mitochondrial ATP by blocking the mitochondrial respiratory chain and ATPase. The main reason for these effects of polyphenols may be that phenolic hydroxyl accepts electrons to form a more stable phenoxy radical, which can protect cellular components from oxidative damage and reduce the risk of various diseases $(44,45)$. García-Lafuente et al. found that flavonoids could alleviate the excess production of free radicals by inhibiting the activity of pro-oxidant enzymes and reactive oxygen species (ROS) production (29). Studies have reported that gallic acid eliminates excess ROS by stimulating the activity of antioxidant enzymes (e.g., glutathione and superoxide dismutase), inhibiting pro-oxidant enzymes (xanthine oxidase, cyclooxygenase) and protecting lipid peroxidation $(42,46)$. Erlank et al. verified that resveratrol or curcumin activated the Nrf2/ARE signaling pathway to alleviate oxidative stress 


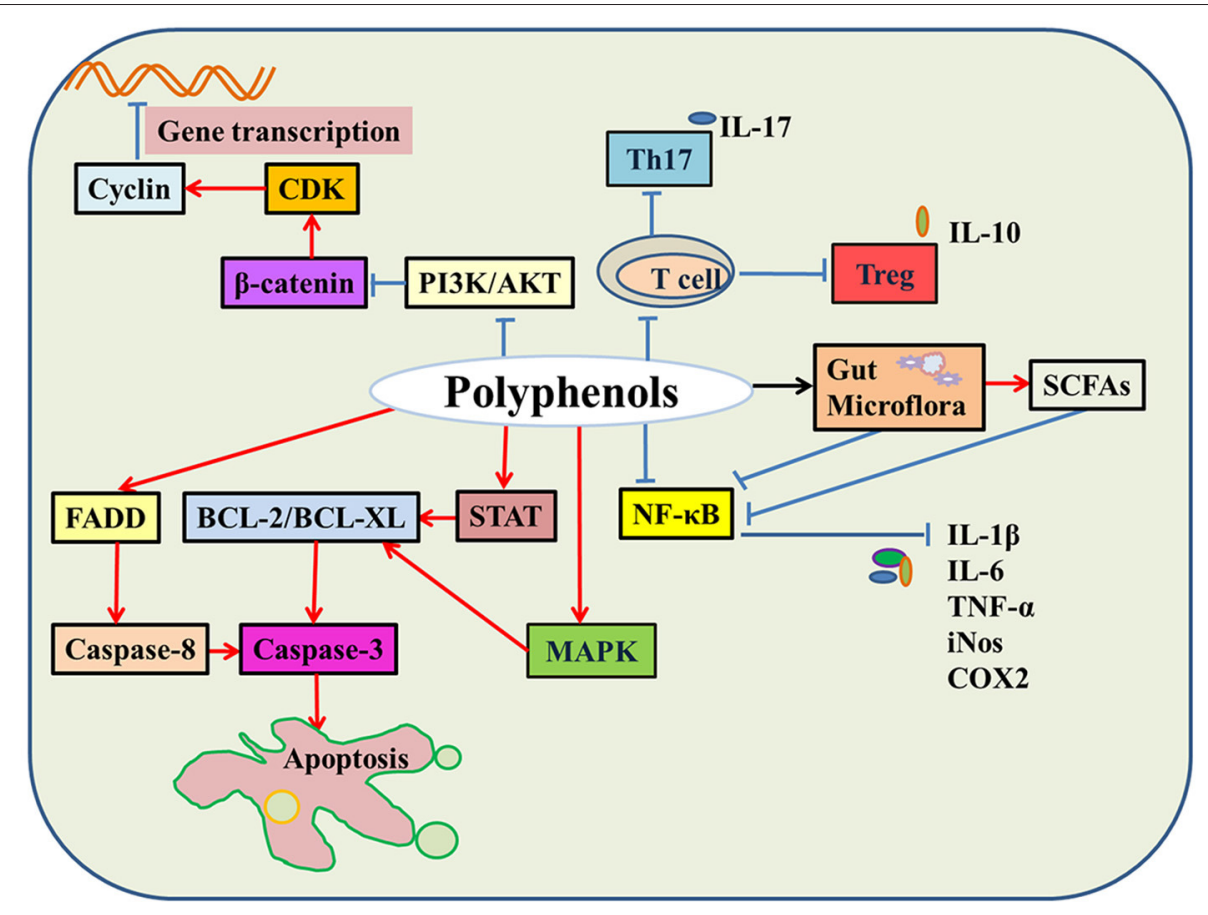

FIGURE 3 | The molecular mechanisms of natural polyphenols in colon cancer. In colon cancer cells, natural polyphenols upregulate the expression of BCL and FADD protein and promote cell apoptosis. Natural polyphenols also downregulate PI3K/AKT and $\beta$-catenin signaling pathways and then hinder cell division. Moreover, natural polyphenols inhibit the activity of immune cells, regulate gut microbes leading to down-regulation of the NF-кB signaling pathway, thereby reducing the release of inflammatory factors, such as IL-6, IL-1 $\beta$, and TNF- $\alpha$ (Red indicates promotion; blue indicates inhibition; black indicates regulation).

TABLE 2 | The study of a variety of polyphenols from different sources in colon cancer.

\begin{tabular}{|c|c|c|}
\hline Polyphenols & Model & Anticancer mechanism \\
\hline Pterostilbene (30) & $\begin{array}{l}\text { Colon carcinogenesis } \\
\text { model in rats }\end{array}$ & 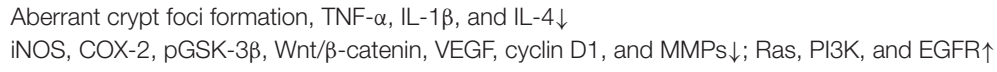 \\
\hline Pterostilbene (31) & HT-29 & $\beta$-catenin, cyclin D1, and c-MYC $\downarrow$ \\
\hline $\begin{array}{l}\text { Cocoa polyphenols } \\
(32,33)\end{array}$ & Caco-2 & $\begin{array}{l}\text { Cyclooxygenase (COX)- } 1 \uparrow \\
\text { NF- } \mathrm{B} \text {, iNOS, TNF- } \alpha \text {, and } \mathrm{pJNK} \downarrow\end{array}$ \\
\hline $\begin{array}{l}\text { Red wine polyphenols } \\
\text { (34) }\end{array}$ & SNU-C4 & 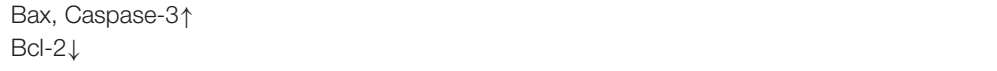 \\
\hline Resveratrol $(35,36)$ & HCT116 & 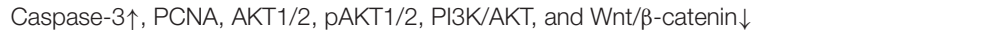 \\
\hline Tea polyphenols (37) & SW480, HT-29 & JAG1, MAFA, HES1, MT2A, BAX, and p38 $\downarrow$ \\
\hline $\begin{array}{l}\text { Olive oil polyphenols } \\
\text { (38) }\end{array}$ & Caco-2 & P38, JNK1/2, NF-кB $\uparrow$, iNOS $\downarrow$ \\
\hline EGCG $(39,40)$ & HCT15, HT-29, CaCo-2 & 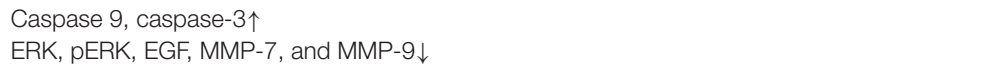 \\
\hline Quercetin (41) & $\begin{array}{l}\text { HT-29, HCT-116, } \\
\text { SW480 }\end{array}$ & $\begin{array}{l}\text { Wnt- } \beta \text {-catenin, Cdc-2, and } \mathrm{p} 21 \uparrow \\
\text { cyclin } A \downarrow\end{array}$ \\
\hline
\end{tabular}

by regulating the expression of key genes associated with antioxidant enzymes and electrophilic reaction elements (35). Moreover, Chedea et al. found that dietary grape pomace polyphenols supplementation increased duodenal superoxide dismutase (SOD) activity and colonic CAT and GSH-PX activity in weaned piglets, while it decreased lipid peroxidation in both duodenum and colon to improve the antioxidant ability (47). Kudingcha polyphenols could have great effect on improving the antioxidant capacity of mice with colitis, the mechanism is that Kudingcha polyphenols treatment could significantly decrease MDA level and increase glutathione (GSH) activity, as well as increased the expression of antioxidant related genes including CuZnSOD, MnSOD, GPX1/4, and CAT in colon (48). However, many reports also revealed that colon cancer cell was easily susceptible to oxidative stress and then resulted in cell apoptosis and growth inhibition (49). For example, polyphenols 
(e.g., epigallocatechin gallate and curcumin) administration would lead to the excessive production of reactive nitrogen species (ROS/RNS), which could damage the cell structure and function $(50,51)$.

\section{Polyphenols as Efficient Regulators of Cell Proliferation and Apoptosis}

The characteristics of colon cancer cells are unlimited proliferation, dedifferentiation and evasive apoptosis. ZamoraRos et al. reported that phenolic acid intake was negatively correlated with colon cancer risk in men, suggesting that dietary phenolic acid could lower the risk of colon cancer (52). For example, some studies have reported that natural polyphenols could reduce the number, weight, and volume of tumors and modify the activity of histone acetyltransferase, histone deacetylase, and methyltransferase; thereby upregulating the expression of tumor suppressor genes in cancer cells $(9,53,54)$. Metabolic changes are one of the most important markers of cell carcinogenesis, which is consistent with a study that reported a new type of polyphenols having inhibitory effects on glycolysis, mitochondrial respiration and ATP production in colon cancer, while activating $5^{\prime}$ AMP-activated protein kinase (AMPK) and inducing cell death (55). Moreover, with tannic acid supplementation, glycolysis was reduced by inhibiting pyruvate kinase activity, resulting in colorectal cancer (CRC) cells proliferation repression (56). Resveratrol increases ROS production via mitochondrial electron transport chain overload, which ultimately affects cell apoptosis or necrosis and even increases cell death $(57,58)$.

In the HCT116 cell inflammatory model, resveratrol treatment upregulated the expression of caspase-3 and tumor suppressor factor (PTEN), downregulated the expression of proliferating cell nuclear antigen (PCNA), AKT1/2, pAKT1/2, and pGSK3 $\beta$, and modulated PI3K/AKT and $\mathrm{Wnt} / \beta$-catenin signaling pathways to regulate cell proliferation and apoptosis (59). The Wnt/ $\beta$-catenin signaling was abnormally overexpressed in colorectal cancer and SW480 colon cancer cells; however, tea polyphenols administration effectively inhibited the Wnt/ $\beta$ catenin signaling pathway to reduce the proliferation of colon cancer cells by activating the GSK3 $\beta$ gene (60). Zeng et al. confirmed that the addition of resveratrol upregulated the expression of bone morphogenetic protein 7 (BMP7) in colon cancer cells and that the activated BMP7 inhibited the PI3K/AKT signaling pathway, which induced the apoptosis of colon cancer cells and exerted anticancer effects (61).

Some studies also found that the effect of resveratrol on the tumor cell cycle was mainly in the occurrence of G2 and S phase arrest. The G2 phase arrest was achieved by inhibiting cyclindependent kinase-7 (CDK7) kinase and cyclin-dependent kinase p34 (CDC2) kinase, while the $S$ phase arrest was achieved by inhibiting the activity of CDK2 and CDK4 and DNA synthesis (62). Delmas et al. demonstrated that resveratrol depended on the conformational changes of the Bax and Bak proteins to control cell apoptosis, which also led to the redistribution of the transmembrane Fas receptor in plasma membrane rafts (63). Some reports have also demonstrated that flavonoids activate the mitogen activated protein kinase (MAPK) cascade cell signaling pathway to restore the redox state of colon cancer cells and reduce the expression of Bax to prevent oxidative stress-induced mitochondrial transition pore complex opening $(64,65)$.

Benhalilou et al. revealed that Origanum marjorana ethanolic extract exerted a cytotoxic effect on colon cancer cells by inducing mitotic arrest, activating autophagy and regulating the caspase 3 and 7-dependent extrinsic apoptotic pathway. It has been further evaluated that the main components of the O. marjorana ethanolic extract are phenols by the high performance liquid chromatography-mass spectrometry (HPLC-MS) analysis (66). Saadatdoust et al. found that cocoa induced cell apoptosis by activating caspase-3 and inhibiting the activation of STAT3 signaling pathways in a mouse model (67). Hu et al. reported that PPEP, a polyphenol-rich extract isolated from edible mushrooms, effectively downregulated the expression of cell cycle-related signaling proteins (e.g., cyclin B and cyclin E) and upregulated the expression of cell apoptosis-related signaling proteins (e.g., caspase-3) in human colon cancer cells, which further caused considerable cell cycle arrest and cell apoptosis (68). These results indicate that natural plant polyphenols could affect glycolysis, mitochondrial respiration, and other metabolic processes, resulting in blocked DNA synthesis, cell cycle arrest, and cell apoptosis.

\section{Polyphenols for the Maintenance of the Gut Microflora}

Gut microflora refers to the large number of microflorae that exists in the intestinal tract of animals, including probiotics, harmful bacteria, and neutral bacteria (69) to maintain intestinal health. In general, probiotics, like Bifidobacteria and Lactobacillus can activate the host immune system to resist a variety of intestinal diseases, such as IBD, irritable bowel syndrome (IBS) and colon cancer (70). It is evident that natural polyphenols could significantly upregulate the abundance of Bifidobacteria and Lactobacillus but inhibit the abundance of the pathogenic bacteria Clostridium and Escherichia coli in order to defend the host against colitis (71-73). It is possible that the use of plant polyphenols can cause the morphological damage to intestinal pathogenic bacteria and disrupt microbial metabolism while protecting the probiotics from damage (74-77). Notably, many studies have reported that there is a crosstalk between polyphenols and their metabolites and intestinal microorganisms (78). Short-chain fatty acids (SCFAs) are produced by the intestinal flora, which serve as the main energy substrate and play an important role in the regulation of intestinal health (79). A recent report has shown that citrus flavanones could also inhibit the growth of pathogens, increase the production of symbiotic bacteria (such as Bifidobacterium and Lactobacillus species), and stimulate the production of SCFAs to alleviate intestinal inflammation (80). Janssen and Kersten (2015) have demonstrated that natural polyphenols participate in the SCFA metabolism of intestinal microbes to affect energy absorption in the host (81).

An imbalance of microbes in the gut increases the risk of obesity and colon cancer (82). And obesity will cause 
mitochondrial dysfunction and reduce oxygen consumption rate in colon cells, which in turn increases susceptibility to colon cancer (83). Dysregulation of intestinal flora activates inflammatory pathways (e.g., NF- $\mathrm{B}, \mathrm{TLR}$, and STAT3) and causes the release of bacterial toxins to accelerate the development of colon cancer. However, many studies have reported that administration of polyphenols could improve the composition of colonic microorganisms or the concentration of metabolites as well as downregulate NF- $\kappa \mathrm{B}$ and TLR signaling pathways to inhibit the development of colon cancer $(84,85)$. Stevens et al. showed that citrus flavanones influenced the abundance of Bifidobacterium, Lactobacillus, and Staphylococcus aureus to alleviate intestinal inflammation (80). Moreover, polyphenols stimulated the production of SCFAs in colon cancer (86), and SCFAs could help shape the stable intestinal microbiological environment. Furthermore, natural polyphenols control the production of lactic acid in gut microbes by regulating the expression of SCFA transporters $(86,87)$. Quercetin and metabolites of chlorogenic acid produced by bacteria, 3, 4-dihydroxyphenylacetic acid, and 3-(3,4-dihydroxybenzene)propionic acid can reduce the expression of cyclooxygenase- 2 in colorectal adenoma cells and regulate the DNA damage induced by cumene hydroperoxide (88). In other words, polyphenolic metabolites produced by the intestinal microflora may directly promote the anticancer action of polyphenols.

\section{Polyphenols as Efficient Suppressors of Inflammation}

Polyphenols regulate the infiltration of immune cells into tumor tissues to enhance immune responses and counteract immune escape, thereby alleviating colon cancer (82). In a CRC experimental model, natural polyphenol supplementation modulated the tumor-associated immunosuppressive microenvironment and inhibited the growth of CRC cells by reducing the colonic infiltration of $\mathrm{CD}^{+} \mathrm{T}$ cells and the number of $\mathrm{CD} 25-\mathrm{FoxP} 3$ regulatory $\mathrm{T}$ cells, increasing the mucosal CD4 ${ }^{+} \mathrm{T}$ and $\mathrm{B}$ cells (89-92). Besides, in a multiple intestinal neoplasia/+ (ApcMin) mice model, cloudberry administration reduced the proportion of $\mathrm{CD}^{+} \mathrm{T}$ lymphocytes, FoxP $3^{+}$regulatory $\mathrm{T}$ lymphocytes, and $\mathrm{CD} 45 \mathrm{R}^{+} \mathrm{B}$ lymphocytes, thereby attenuating intestinal inflammation (93). A previous study demonstrated that curcumin supplementation inhibited the suppressive activity of Treg cells by downregulating the production of TGF- $\beta$ and IL-10, which could enhance the ability of effector T cells to kill cancer cells (94). The increase in Th17 cells in patients with metastatic colorectal cancer is associated with poor prognosis (95). The Th17 cells enhanced tumor cell resistance to apoptosis and proliferation by promoting Il-17 secretion, and the Th17 cells were reduced after red wine extract treatment (red wine polyphenols), which might have been the cause of delayed tumor growth $(96,97)$. Furthermore, treatment with resveratrol could regulate the balance of Treg/Th17 and the levels of intestinal mucosal cytokines, including IL-10, TGF- $\beta$, IL-6, and IL-17, in an ulcerative colitis mouse model (98). Cocoa has been demonstrated to affect the gut immune responses by increasing the percentage of $\gamma \delta \mathrm{T}$ cells and weakening the effect of
IgA in young rats (99). Oz et al. found that green tea polyphenols could decrease the levels of inflammatory cytokines TNF- $\alpha$ and IL-6 and improve antioxidant enzyme levels in patients with colitis (100). Emerging evidence indicates that the rat with colitis has the properties for the increased intestinal permeability and impaired barrier function; flavonoids treatment could maintain intestinal permeability and increase the expression and tight junction protein to alleviate colitis $(80,101)$.

Recent studies have demonstrated that polyphenols exert therapeutic and preventive effects against colon cancer by modulating multiple signaling pathways both in vitro and in vivo, such as the NF-кB pathway, MAPK pathway, PI3K/AKT pathway, Wnt/ $\beta$-catenin pathway, and $c$-Jun $\mathrm{N}$-terminal kinase (JNK) pathway $(102,103)$. The NF- $\mathrm{B}$ pathway, a major inflammatory signaling pathway, promotes the production of iNOS, COX-2, and proinflammatory cytokines (IL-1, IL-2, IL-6, and $T N F-\alpha$ ) to stimulate the inflammatory response (104). Many reports have shown that COX-2 is expressed in large quantities in colon tumor cells, and COX-2 silencing or knockout inhibits the invasive potential of CRC cells and decreases the metastatic potential of colorectal tumor cells $(105,106)$. Previous studies have shown that curcumin reduced the expression of COX-2, iNOS, and TNF genes and inhibited the protein expression of NF$\kappa \mathrm{B}, \mathrm{cJNK}$, protein tyrosine kinases and protein serine/threonine kinases (GSK-3 $\beta$ ), further depressing tumorigenesis (107). In addition, cocoa polyphenols decreased the expression of the inflammatory marker COX-2 and nitric oxide (NO) synthase pro-inflammatory enzymes and suppressed NF-кB nuclear translocation and JNK phosphorylation to relieve colon cancer $(32,108)$. In contrast, gallic acid equivalent (GAE) treatment increased intracellular ROS production in human cancer colon fibroblast cells and decreased the expression levels of TNF- $\alpha$, IL$1 \beta$, IL-6, and NF- $\kappa$ B to suppress cell proliferation (109). However, in human non-cancer colon fibroblast cells, GAE promoted antiinflammatory activities, which was accompanied by the reduction of intracellular ROS and the inhibited expression of TNF- $\alpha$, IL$1 \beta$, IL-6, and NF- $\kappa$ B (109). These results suggest that polyphenols may play a key role in preventing colon cancer by modulating the production of inflammatory cytokines and the activation of immune cells and key signaling pathways to regulate the inflammatory tumor microenvironment.

\section{APPLICATION OF POLYPHENOLS IN DISEASE PREVENTION}

Polyphenols have a wide range of applications in the food, medical, and pharmaceutical fields owing to their multiple health benefits, including antioxidant and antibacterial activities, cancer prevention, antiradiation effects, and immune enhancement. It is known that colon cancer cells develop drug resistance under chemotherapy conditions, but polyphenols intervention, like curcumin, which can promote apoptosis of cancer stem cells and reduce drug resistance (41). However, polyphenols have significant anticancer potential in in vitro cell culture and in vivo animal models, there were only very few clinical trials to prove the effectiveness of dietary polyphenols in the 
prevention and treatment of cancer due to challenges, such as ineffective stability, and low bioavailability. The utilization of polyphenols is low due to the metabolism of host enzymes (e.g., lactase-phlorizin hydrolase and cytosolic $\beta$-glucosidase) and intestinal microorganisms (110). Therefore, we should focus on improving the bioavailability of polyphenols in future studies. For example, Tabrez et al. showed that nanoencapsulation can extend circulation, improve localization, enhance efficacy, and reduce the chance of multidrug resistance (111). Thus, polyphenol nanomaterials are promising in the clinical treatment of colon cancer.

Besides, some studies have shown that natural polyphenols have effects on various bacteria, fungi, and yeasts, such as the cholera bacteria, S. aureus, E. coli, and other common pathogenic bacteria (25). Flavonols are commonly used to treat Microsporum gypseum, Trichophyton mentagrophytes, and Trichophyton rubrum to alleviate the allergic reaction of bacterial and fungal dermatitis (112). Proanthocyanidins can prevent viruses from entering host cells, such as influenza A virus and herpes simplex virus type 1 (113). Different kinds of polyphenols (i.e., flavanones, green tea polyphenols, red wine polyphenols, and resveratrol) have been valued primarily as crucial regulators in both in vivo and in vitro inflammatory models and can be used as potential agents to treat diseases, such as diabetes, obesity, and cardiovascular diseases (27). For example, flavanones, an effective inhibitor of low-density lipoprotein, might provide a protective effect against cardiovascular and chronic inflammatory diseases (114).

\section{CONCLUSIONS AND PERSPECTIVES}

Numerous studies have reported that natural plant polyphenols are critical modulators of intestinal flora, inflammation, cell cycle, and apoptosis in colon cancer, making them a potential therapeutic agent. To date, an increasing number of dietary plant polyphenols has been used as anticancer agents to prevent and treat colon cancer or other intestinal diseases. Furthermore, the regulatory mechanisms of natural plant polyphenols on intestinal flora, inflammation, and cancer-cell proliferation and death have become clear in tumor cells, including the STAT, NF- $\kappa$ B, Wnt $/ \beta$ catenin, PI3K/Akt, and apoptosis-related signaling pathways.

Natural polyphenols are promising candidates for the prevention and treatment of colon cancer. However, many biochemical mechanisms and clinical applications of plant polyphenols in colon cancer remain to be further resolved, such as metabolism in the gastrointestinal tract and visceral tissue, synergistic effect of polyphenols with drugs or diverse chemotherapeutics, and targeted therapies. Importantly, for the use of polyphenols as a potential targeted therapy, the targeted regulatory sites should be determined and targeted inhibitors developed in the future. Therefore, the relationship between colon cancer and plant polyphenols needs to be further clarified. In addition, large-scale biological production of dietary plant polyphenols has not been extensively investigated and will be one of our future research projects.

\section{AUTHOR CONTRIBUTIONS}

JLo and PG wrote the manuscript. TL, LH, JLo, XHu, ZD, FL, and LY discussed the topic. JLi, QL, XHe, and $\mathrm{LH}$ revised the manuscript. All authors contributed to the article and approved the submitted version.

\section{FUNDING}

This work was supported by Natural Science Foundation of China (31902168 and 31872371), Young Elite Scientists Sponsorship Program by CAST (2019QNRC001), Huxiang Young Talents Plan Project of Hunan Province (2020RC3052), Guangdong Basic and Applied Basic Research Fund Project (2019A1515110852), the National Science Foundation for Outstanding Young Scholars of Hunan Province (2019JJ30017), Hunan high-level talent gathering project (2018RS3111), Hunan Science and Technology Leading Talent Project (2019RS3022), and Guangxi Key Research and Development Plan (guike AB19259012).

\section{REFERENCES}

1. Aquina CT, Mohile SG, Tejani MA, Becerra AZ, Xu Z, Hensley BJ, et al. The impact of age on complications, survival, and cause of death following colon cancer surgery. Br J Cancer. (2017) 116:389-97. doi: 10.1038/bjc.2016.421

2. Manjelievskaia J, Brown D, McGlynn KA, Anderson W, Shriver $\mathrm{CD}$, Zhu K. Chemotherapy use and survival among young and middle-aged patients with colon cancer. JAMA Surg. (2017) 152:452-9. doi: 10.1001/jamasurg.2016.5050

3. Wang ZJ, Ohnaka K, Morita M, Toyomura K, Kono S, Ueki T, et al. Dietary polyphenols and colorectal cancer risk: the Fukuoka colorectal cancer study. World J Gastroenterol. (2013) 19:2683-90. doi: 10.3748/wjg.v19.i17.2683

4. Derry MM, Raina K, Agarwal C, Agarwal R. Identifying molecular targets of lifestyle modifications in colon cancer prevention. Front Oncol. (2013) 3:119. doi: $10.3389 /$ fonc. 2013.00119

5. Saxena Baliga MS, Ponemone V, Kaur K, Larsen B, Fletcher E, Greene J, et al. Mucus and adiponectin deficiency: role in chronic inflammation-induced colon cancer. Int J Colorectal Dis. (2013) 28:126779. doi: $10.1007 / \mathrm{s} 00384-013-1664-2$

6. Saxena Chumanevich A, Fletcher E, Larsen B, Lattwein K, Kaur K, Fayad R. Adiponectin deficiency: role in chronic inflammation induced colon cancer. Biochim Biophys Acta. (2012) 1822:527-36. doi: 10.1016/j.bbadis.2011.12.006

7. Grady WM, Markowitz SD. The molecular pathogenesis of colorectal cancer and its potential application to colorectal cancer screening. Dig Dis Sci. (2015) 60:762-72. doi: 10.1007/s10620-014-3444-4

8. Akiyama Y, Kimura Y, Enatsu R, Mikami T, Wanibuchi M, Mikuni N. Advantages and disadvantages of combined chemotherapy with carmustine wafer and bevacizumab in patients with newly diagnosed glioblastoma: a single-institutional experience. World Neurosurg. (2018) 113:e50814. doi: 10.1016/j.wneu.2018.02.070

9. Bar-Shalom R, Bergman M, Graossman S, Azzam N, Sharvit L, Fares F. Viscosa extract inhibits growth of colorectal cancer cells in vitro and in vivo through induction of apoptosis. Front Oncol. (2019) 9:227. doi: 10.3389/fonc.2019.00227

10. Ohno M, Nishida A, Sugitani Y, Nishino K, Inatomi O, Sugimoto M, et al. Nanoparticle curcumin ameliorates experimental colitis via modulation of gut microbiota and induction of regulatory T cells. PLoS ONE. (2017) 12:e0185999. doi: 10.1371/journal.pone.0185999 
11. Carrasco-Pozo Morales P, Gotteland M. Polyphenols protect the epithelial barrier function of caco-2 cells exposed to indomethacin through the modulation of occludin and zonula occludens-1 expression. J Agric Food Chem. (2013) 61:5291-7. doi: 10.1021/jf400150p

12. Zhao Y, Jiang Q. Roles of the polyphenol-gut microbiota interaction in alleviating colitis and preventing colitis-associated colorectal cancer. Adv Nutr. (2020) 1-20. doi: 10.1093/advances/nmaa104

13. Lapornik Prosek M, Wondra AG. Comparison of extracts prepared from plant by-products using different solvents and extraction time. J Food Eng. (2005) 71:214-22. doi: 10.1016/j.jfoodeng.2004.10.036

14. Chiva-Blanch G, Badimon L. Effects of polyphenol intake on metabolic syndrome: current evidences from human trials. Oxid Med Cell Longev. (2017) 2017:5812401. doi: 10.1155/2017/5812401

15. Khan H, Reale M, Ullah H, Sureda A, Tejada S, Wang Y, et al. Anti-cancer effects of polyphenols via targeting p53 signaling pathway: updates and future directions. Biotechnol Adv. (2020) 38:107385. doi: 10.1016/j.biotechadv.2019.04.007

16. Ding Y, Yao H, Yao Y, Fai LY, Zhang Z. Protection of dietary polyphenols against oral cancer. Nutrients. (2013) 5:2173-91. doi: 10.3390/nu5062173

17. Arora Sharma M, Tollefsbol TO. Combinatorial epigenetics impact of polyphenols and phytochemicals in cancer prevention and therapy. Int J Mol Sci. (2019) 20:4567. doi: 10.3390/ijms20184567

18. Bravo L, Polyphenols: chemistry, dietary sources, metabolism, nutritional significance. Nutr Rev. (1998) 56:31733. doi: 10.1111/j.1753-4887.1998.tb01670.x

19. Tsao R, Chemistry and biochemistry of dietary polyphenols. Nutrients. (2010) 2:1231-46. doi: 10.3390/nu2121231

20. Uyama H, Kobayashi S. Enzymatic synthesis of polyphenols. Curr Org Chem. (2003) 7:1387-97. doi: 10.2174/1385272033486459

21. Carter LG, D'Orazio JA, Pearson KJ. Resveratrol and cancer: focus on in vivo evidence. Endocr Relat Cancer. (2014) 21:R209-25. doi: 10.1530/ERC-13-0171

22. Moreira H, Slezak A, Szyjka A, Oszmianski J, Gasiorowski K. Antioxidant and cancer chemopreventive activities of cistus and pomegranate polyphenols. Acta Pol Pharm. (2017) 74:688-98.

23. Arranz S, Chiva-Blanch G, Valderas-Martínez P, Medina-Remón A, Lamuela-Raventós RM, Estruch R. Wine, beer, alcohol and polyphenols on cardiovascular disease and cancer. Nutrients. (2012) 4:759-81. doi: 10.3390/nu4070759

24. Jamar G, Estadella D, Pisani LP. Contribution of anthocyanin-rich foods in obesity control through gut microbiota interactions. Biofactors. (2017) 43:507-16. doi: 10.1002/biof.1365

25. Gowd V, Karim N, Shishir MRI, Xie L, Chen W. Dietary polyphenols to combat the metabolic diseases via altering gut microbiota. Trends Food Sci Technol. (2019) 93:81-93. doi: 10.1016/j.tifs.2019.09.005

26. Guergoletto KB, Costabile A, Flores G, Garcia S, Gibson GR. In vitro fermentation of juçara pulp (Euterpe edulis) by human colonic microbiota. Food Chem. (2016) 196:251-8. doi: 10.1016/j.foodchem.2015. 09.048

27. Pandey KB, Rizvi SI. Plant polyphenols as dietary antioxidants in human health and disease. Oxid Med Cell Longev. (2009) 2:2708. doi: 10.4161/oxim.2.5.9498

28. Marín L, Miguélez EM, Villar CJ, Lombó F. Review article bioavailability of dietary polyphenols and gut microbiota metabolism: antimicrobial properties. Biomed Res Int. (2015) 2015:905215. doi: 10.1155/2015/9 05215

29. García-Lafuente A, Guillamón E, Villares A, Rostagno MA, Martínez JA. Flavonoids as anti-inflammatory agents: implications in cancer and cardiovascular disease. Inflamm. Res. (2009) 58:537-52. doi: 10.1007/s00011-009-0037-3

30. Estrela M, Ortega A, Mena S, Rodriguez ML, Asensi M. Pterostilbene: biomedical applications. Crit Rev Clin Lab Sci. (2013) 50:65-78. doi: 10.3109/10408363.2013.8 05182

31. Nassar D, Blanpain C. Cancer stem cells: basic concepts and therapeutic implications. Annu Rev Pathol. (2016) 11:4776. doi: 10.1146/annurev-pathol-012615-044438
32. Rodríguez-Ramiro Ramos S, López-Oliva E, Agis-Torres A, Bravo L, Goya L, Martín MA. Cocoa polyphenols prevent inflammation in the colon of azoxymethane-treated rats and in TNF- $\alpha$-stimulated Caco- 2 cells. Br J Nutr. (2013) 110:206-15. doi: 10.1017/S0007114512004862

33. Magrone T, Russo MA, Jirillo E. Cocoa and dark chocolate polyphenols: from biology to clinical applications. Front Immunol. (2017) 8:677. doi: 10.3389/fimmu.2017.00677

34. Kim J, Kim YJ, Park HJ, Chung JH, Leem KH, Kim HK. Apoptotic effect of red wine polyphenols on human colon cancer SNU-C4 cells. Food Chem Toxicol. (2006) 44:898-902. doi: 10.1016/j.fct.2005.08.031

35. Erlank H, Elmann A, Kohen R, Kanner J. Polyphenols activate Nrf2 in astrocytes via $\mathrm{H}_{2} \mathrm{O}_{2}$, semiquinones, and quinones. Free Radic Biol Med. (2011) 51:2319-27. doi: 10.1016/j.freeradbiomed.2011.09.033

36. Ding $S$, $\mathrm{Xu} \mathrm{S}$, Fang J, Jiang $\mathrm{H}$. The protective effect of polyphenols for colorectal cancer. Front Immunol. (2020) 11:1407. doi: 10.3389/fimmu.2020.01407

37. Jin $\mathrm{H}$, Tan X, Liu X, Ding Y. The study of effect of tea polyphenols on microsatellite instability colorectal cancer and its molecular mechanism. Int J Colorectal Dis. (2010) 25:1407-15. doi: 10.1007/s00384-010-1047-x

38. Serra G, Incani A, Serreli G, Porru L, Melis MP, Tuberoso CIG, et al. Olive oil polyphenols reduce oxysterols-induced redox imbalance and pro-inflammatory response in intestinal cells. Redox Biol. (2018) 17:34854. doi: 10.1016/j.redox.2018.05.006

39. Shimizu Deguchi A, Hara Y, Moriwaki H, Weinstein IB. EGCG inhibits activation of the insulin-like growth factor-1 receptor in human colon cancer cells. Biochem Biophys Res Commun. (2005) 334:94753. doi: 10.1016/j.bbrc.2005.06.182

40. Wei R, Wirkus J, Yang Z, Machuca J, Esparza Y, Mackenzie GG. EGCG sensitizes chemotherapeutic-induced cytotoxicity by targeting the ERK pathway in multiple cancer cell lines. Arch Biochem Biophys. (2020) 692:108546. doi: 10.1016/j.abb.2020.108546

41. Su PF, Yang Y, Wang GX, Chen XW, Ju YL. Curcumin attenuates resistance to irinotecan via induction of apoptosis of cancer stem cells in chemoresistant colon cancer cells. Int J Oncol. (2018) 53:1343-53. doi: 10.3892/ijo.201 8.4461

42. Badhani B, Sharma N, Kakkar R. Gallic acid: a versatile antioxidant with promising therapeutic and industrial applications. RSC Adv. (2015) 05:27540-57. doi: 10.1002/chin.201523286

43. Chow SE, Hshu YC, Wang JS, Chen JK. Resveratrol attenuates oxLDL-stimulated NADPH oxidase activity and protects endothelial cells from oxidative functional damages. J Appl Physiol. (2007) 102:1520-7. doi: 10.1152/japplphysiol.00881.2006

44. Clifford MN, Lindsay D, Clifford M. Chlorogenic acids and other cinnamates-nature, occurrence, dietary burden, absorption and metabolism. J Sci Food Agric. (2000) 80:1033-43. doi: 10.1002/(SICI)10970010(20000515)80:7<1033::AID-JSFA595>3.0.CO;2-T

45. Suaib LR. Syed Ibrahim, Protection of lipid peroxidation and carbonyl formation in proteins by capsaicin in human erythrocytes subjected to oxidative stress. Phytother Res. (2010) 20:303-6. doi: 10.1002/ptr.1861

46. Denev PN, Ch K, Ciz M, Lojek A, Kratchanova MG. Bioavailability and antioxidant activity of black chokeberry (Aronia melanocarpa) polyphenols: in vitro and in vivo evidences and possible mechanisms of action. Compr Rev Food Sci Food Saf. (2012) 11:471-89. doi: 10.1111/j.1541-4337.2012.00198.x

47. Chedea VS, Palade LM, Marin DE, Pelmus RS, Habeanu M, Rotar MC, et al. Intestinal absorption and antioxidant activity of grape pomace polyphenols. Nutrients. (2018) 10:24. doi: 10.3390/nu10050588

48. Long X, Pan Y, Zhao X. Prophylactic effect of Kudingcha polyphenols on oxazolone induced colitis through its antioxidant capacities. Food Sci Hum Well. (2018) 7:209-14. doi: 10.1016/j.fshw.2018.06.002

49. Olejnik Kaczmarek M, Olkowicz M, Kowalska K, Juzwa W, Dembczynski R. ROS-modulating anticancer effects of gastrointestinally digested Ribes nigrum L. J Funct Foods. (2018) 42:224-36. doi: 10.1016/j.jff.2018.01.011

50. Wang Schuller Levis GB, Lee EB, Levis WR, Lee DW, Kim BS, Park SY, et al. Platycodin D and D3 isolated from the root of Platycodon grandiflorum modulate the production of nitric oxide and secretion of TNF-alpha in activated RAW 264.7 cells. Int Immunopharmacol. (2004) 4:1039-49. doi: 10.1016/j.intimp.2004.04.005 
51. Yahfoufi N, Alsadi N, Jambi M, Matar C. The immunomodulatory and anti-inflammatory role of polyphenols. Nutrients. (2018) 10:1618. doi: 10.3390/nu10111618

52. Zamora-Ros R, Cayssials V, Jenab M, Rothwell JA, Fedirko V, Aleksandrova $\mathrm{K}$, et al. Dietary intake of total polyphenol and polyphenol classes and the risk of colorectal cancer in the European Prospective Investigation into Cancer and Nutrition (EPIC) cohort. Eur J Epidemiol. (2018) 33:106375. doi: 10.1007/s10654-018-0408-6

53. Tresserra-Rimbau Lamuela-Raventos RM, Moreno JJ. Polyphenols, food and pharma. Current knowledge and directions for future research. Biochem Pharmacol. (2018) 156:186-95. doi: 10.1016/j.bcp.2018.07.050

54. Yang S, Landau JM, Huang MT, Newmark HL. Inhibition of carcinogenesis by dietary polyphenolic compounds. Annu Rev Nutr. (2001) 21:381406. doi: 10.1146/annurev.nutr.21.1.381

55. Gómez de Cedrón M, Vargas T, Madrona A, Jiménez A, Pérez-Pérez MJ, Quintela JC, Reglero G, et al. Ramírez de Molina, novel polyphenols that inhibit colon cancer cell growth affecting cancer cell metabolism. J Pharmacol Exp Ther. (2018) 366:377-89. doi: 10.1124/jpet.118.2 48278

56. Yang P, Ding GB, Liu W, Fu R, Sajid A, Li Z. Tannic acid directly targets pyruvate kinase isoenzyme $\mathrm{M} 2$ to attenuate colon cancer cell proliferation. Food funct. (2018) 9:5547-59. doi: 10.1039/C8FO01161C

57. del Mar Blanquer-Rosselló M, Hernández-López R, Roca P, Oliver J, Valle A. Resveratrol induces mitochondrial respiration and apoptosis in SW620 colon cancer cells. Biochim Biophys Acta. (2017) 1861:43140. doi: 10.1016/j.bbagen.2016.10.009

58. Juan ME, Alfaras I, Planas JM. Colorectal cancer chemoprevention by trans-resveratrol. Pharmacol. Res. (2012) 65:58491. doi: 10.1016/j.phrs.2012.03.010

59. Liu YZ, Wu K, Huang J, Liu Y, Wang X, Meng ZJ, et al. The PTEN/PI3K/Akt and $\mathrm{Wnt} / \beta$-catenin signaling pathways are involved in the inhibitory effect of resveratrol on human colon cancer cell proliferation. Int J Oncol. (2014) 45:104-12. doi: 10.3892/ijo.2014.2392

60. Oh S, Gwak J, Park S, Yang CS. Green tea polyphenol EGCG suppresses Wnt/beta-catenin signaling by promoting GSK-3 beta- and PP2Aindependent beta-catenin phosphorylation/degradation. Biofactors. (2014) 40:586-95. doi: 10.1002/biof.1185

61. Zeng YH, Zhou LY, Chen QZ, Li Y, Shao Y, Ren WY, et al. Resveratrol inactivates PI3K/Akt signaling through upregulating BMP7 in human colon cancer cells. Oncol Rep. (2017) 38:456-64. doi: 10.3892/or.2017.5662

62. Feng M, Zhong L-X, Zhan Z-Y, Huang Z-H, Xiong J-P. Resveratrol treatment inhibits proliferation of and induces apoptosis in human colon cancer cells. Med Sci Monit. (2016) 22:1101-8. doi: 10.12659/MSM.897905

63. Delmas Rébé C, Lacour S, Filomenko R, Athias A, Gambert P, CherkaouiMalki $\mathrm{M}$, et al. Resveratrol-induced apoptosis is associated with Fas redistribution in the rafts and the formation of a death-inducing signaling complex in colon cancer cells. J Biol Chem. (2003) 278:4148290. doi: $10.1074 /$ jbc.M304896200

64. Williams RJ, Spencer JPE, Catherine RE. Flavonoids: antioxidants or signalling molecules? Free Radic Biol Med. (2004) 36:83849. doi: 10.1016/j.freeradbiomed.2004.01.001

65. Mandel S, Youdim MBH. Catechin polyphenols: neurodegeneration and neuroprotection in neurodegenerative diseases?. Free Radic. Biol. Med. (2004) 37:304-17. doi: 10.1016/j.freeradbiomed.2004.04.012

66. Benhalilou N, Alsamri H, Alneyadi A, Athamneh K, Alrashedi A, Altamimi $\mathrm{N}$, et al. Origanum majorana ethanolic extract promotes colorectal cancer cell death by triggering abortive autophagy and activation of the extrinsic apoptotic pathway. Front Oncol. (2019) 9:795. doi: 10.3389/fonc.2019.00795

67. Saadatdoust Z, Pandurangan AK, Ananda Sadagopan SK, Mohd Esa N, Ismail A, Mustafa MR. Dietary cocoa inhibits colitis associated cancer: a crucial involvement of the IL-6/STAT3 pathway. J Nutr Biochem. (2015) 26:1547-58. doi: 10.1016/j.jnutbio.2015.07.024

68. Hu Q, Yuan B, Xiao H, Zhao L, Wu X, Rakariyatham K, et al. Polyphenolsrich extract from Pleurotus eryngii with growth inhibitory of HCT116 colon cancer cells and anti-inflammatory function in RAW264. 7 cells. Food Funct. (2018) 9:1601-11. doi: 10.1039/C7FO01794D
69. Eckburg PB, Bik EM, Bernstein CN, Purdom E, Dethlefsen L, Sargent M, et al. Diversity of the human intestinal microbial flora. Science. (2005) 308:1635-8. doi: 10.1126/science.1110591

70. O'Callaghan A, van Sinderen D. Bifidobacteria and their role as members of the human gut microbiota. Front Microbiol. (2016) 7:23. doi: $10.3389 /$ fmicb.2016.00925

71. Bialonska D, Ramnani P, Kasimsetty SG, Muntha KR, Gibson GR, Ferreira D. The influence of pomegranate by-product and punicalagins on selected groups of human intestinal microbiota. Int J Food Microbiol. (2010) 140:17582. doi: 10.1016/j.ijfoodmicro.2010.03.038

72. Firrman J, Liu L, Zhang L, Argoty GA, Wang M, Tomasula P, et al. The effect of quercetin on genetic expression of the commensal gut microbes Bifidobacterium catenulatum, Enterococcus caccae and Ruminococcus gauvreauii. Anaerobe. (2016) 42:130-41. doi: 10.1016/j.anaerobe.2016.10.004

73. Hui CL, Jenner AM, Low CS, Yuan KL. Effect of tea phenolics and their aromatic fecal bacterial metabolites on intestinal microbiota. Res in Microbiol. (2006) 157:876-84. doi: 10.1016/j.resmic.2006. 07.004

74. Li R, Fei P, Man CX, Lou BB, Niu JT, Feng J, et al. Tea polyphenols inactivate Cronobacter sakazakii isolated from powdered infant formula. J Dairy Sci. (2016) 99:1019-28. doi: 10.3168/jds.2015-10039

75. Li Xu Y, Wang X, Zhang B, Shi C, Zhang W, Xia X. Tannin-rich fraction from pomegranate rind damages membrane of Listeria monocytogenes. Foodborne Pathog Dis. (2014) 11:313-9. doi: 10.1089/fpd.201 3.1675

76. Xu YF, Shi C, Wu Q, Zheng ZW, Liu PF, Li GH, et al. Antimicrobial activity of Punicalagin against Staphylococcus aureus and its effect on biofilm formation. Foodborne Pathog Dis. (2017) 14:282-7. doi: 10.1089/fpd.2016.2226

77. Di Pasqua R, Mamone G, Ferranti P, Ercolini D, Mauriello G. Changes in the proteome of Salmonella enterica serovar Thompson as stress adaptation to sublethal concentrations of thymol. Proteomics. (2010) 10:1040-9. doi: $10.1002 /$ pmic.200900568

78. Cardona Andres-Lacueva C, Tulipani S, Tinahones FJ, Queipo-Ortuno MI. Benefits of polyphenols on gut microbiota and implications in human health. J Nutr Biochem. (2013) 24:1415-22. doi: 10.1016/j.jnutbio.2013. 05.001

79. Tan J, McKenzie C, Potamitis M, Thorburn AN, Mackay CR, Macia L. The role of short-chain fatty acids in health and disease. Adv Immunol. (2014) 121:91-119. doi: 10.1016/B978-0-12-800100-4.00003-9

80. Stevens Y, Rymenant EV, Grootaert C, Camp JV, Possemiers S, Masclee A, et al. The intestinal fate of citrus flavanones and their effects on gastrointestinal health. Nutrients. (2019) 11:1464. doi: 10.3390/nu110 71464

81. Janssen WF, Kersten S. The role of the gut microbiota in metabolic health. Faseb J. (2015) 29:3111-23. doi: 10.1096/fj.14-269514

82. Mileo M, Nisticò P, Miccadei S. Polyphenols: immunomodulatory and therapeutic implication in colorectal cancer. Front Immunol. (2019) 10:729. doi: 10.3389/fimmu.2019.00729

83. Schwartz B, Yehuda-Shnaidman E. Putative role of adipose tissue in growth and metabolism of colon cancer cells. Front Oncol. (2014) 4:164. doi: $10.3389 /$ fonc. 2014.00164

84. Rubin C, Shaker A, Levin MS. Chronic intestinal inflammation, inflammatory bowel disease and colitis-associated colon cancer. Front Immunol. (2012) 3:107. doi: 10.3389/fimmu.2012.00107

85. Singh N, Gurav A, Sivaprakasam S, Brady E, Padia R, Shi H, et al. Activation of Gpr109a, receptor for niacin and the commensal metabolite butyrate, suppresses colonic inflammation and carcinogenesis. Immunity. (2014) 40:128-39. doi: 10.1016/j.immuni.2013.12.007

86. Ríos-Covián Ruas-Madiedo P, Margolles A, Gueimonde M CG. de Los Reyes-Gavilán and Salazar N, intestinal short chain fatty acids and their link with diet and human health. Front Microbiol. (2016) 7:1855. doi: $10.3389 /$ fmicb.2016.00185

87. Wang Yu Y, Wang YZ, Wang JJ, Guan R, Sun Y, Shi F, et al. Role of SCFAs in gut microbiome and glycolysis for colorectal cancer therapy. J Cell Physiol. (2019) 234:17023-49. doi: 10.1002/jcp.28436 
88. Miene C, Weise A, Glei M. Impact of polyphenol metabolites produced by colonic microbiota on expression of COX-2 and GSTT2 in human colon cells (LT97). Nutr Cancer. (2011) 63:653-62. doi: 10.1080/01635581.2011.552157

89. Zhang Z, Wu X, Cao S, Cromie M, Shen Y, Feng Y, et al. Chlorogenic acid ameliorates experimental colitis by promoting growth of Akkermansia in mice. Nutrients. (2017) 9:677. doi: 10.3390/nu9070677

90. Cui X, Jin Y, Hofseth AB, Pena E, Habiger J, Chumanevich A, et al. Resveratrol suppresses colitis and colon cancer associated with colitis. Cancer Prev Res. (2010) 3:549-59. doi: 10.1158/1940-6207.CAPR-09-0117

91. Churchill M, Chadburn A, Bilinski RT, Bertagnolli MM. Inhibition of intestinal tumors by curcumin is associated with changes in the intestinal immune cell profile. J Surg Res. (2000) 89:169-75. doi: 10.1006/jsre.2000.5826

92. Hong EH, Heo EY, Song JH, Kwon BE, Lee JY, Park Y, et al. Trans-scirpusin a showed antitumor effects via autophagy activation and apoptosis induction of colorectal cancer cells. Oncotarget. (2017) 8:41401. doi: 10.18632/oncotarget. 17388

93. Essi P, Mikael N, Johanna M, Markus S, Anu HL, Maria S, et al. Changes in intestinal immunity, gut microbiota, and expression of energy metabolismrelated genes explain adenoma growth in bilberry and cloudberry-fed Apc $^{\text {Min }}$ mice. Nutr Res. (2016) 36:1285-97. doi: 10.1016/j.nutres.2016.10.003

94. Bhattacharyya S, Hossain DMS, Mohanty S, Sen GS, Chattopadhyay $\mathrm{S}$, Banerjee $\mathrm{S}$, et al. Curcumin reverses $\mathrm{T}$ cell-mediated adaptive immune dysfunctions in tumor-bearing hosts. Cell Mol Immunol. (2010) 7:306. doi: $10.1038 / \mathrm{cmi} .2010 .11$

95. Limagne Euvrard R, Thibaudin M, Rébé C, Derangère V, Chevriaux A, Boidot R, et al. accumulation of MDSC and Th17 cells in patients with metastatic colorectal cancer predicts the efficacy of a FOLFOXbevacizumab drug treatment regimen. Cancer Res. (2016) 76:524152. doi: 10.1158/0008-5472.CAN-15-3164

96. Loncle C, Bonjoch L, Folch-Puy E, Lopez-Millan MB, Lac S, Molejon MI, et al. IL17 functions through the novel REG3 $\beta$ JAK2-STAT3 inflammatory pathway to promote the transition from chronic pancreatitis to pancreatic cancer. Cancer Res. (2015) 75:4852-62. doi: 10.1158/0008-5472.CAN-15-0896

97. Chalons P, Courtaut F, Limagne E, Chalmin F, Cantos-Villar E, Richard T, et al. Red wine extract disrupts th17 lymphocyte differentiation in a colorectal cancer context. Mol Nutr Food Res. (2020) 64:e1901286. doi: 10.1002/mnfr.201901286

98. Yao Wei C, Wang JY, Zhang R, Li YX, Wang LS. Effect of resveratrol on Treg/Th17 signaling and ulcerative colitis treatment in mice. World J Gastroenterol. (2015) 21:6572. doi: 10.3748/wjg.v21.i21.6572

99. Ramiro-Puig E, Pérez-Cano FJ, Ramos-Romero S, Pérez-Berezo T, Castellote C, Permanyer J, et al. Intestinal immune system of young rats influenced by cocoa-enriched diet. J Nutr Biochem. (2008) 19:55565. doi: 10.1016/j.jnutbio.2007.07.002

100. Oz HS, Chen T, de Villiers WS. Green tea polyphenols and sulfasalazine have parallel anti-inflammatory properties in colitis models. Front Immunol. (2013) 4:132. doi: 10.3389/fimmu.2013.00132

101. Fukui H. Increased intestinal permeability and decreased barrier function: does it really influence the risk of inflammation? Inflamm Intest Dis. (2016) 1:135-45. doi: 10.1159/000447252

102. Li W, Mei X, Tu YY. Effects of tea polyphenols and their polymers on MAPK signaling pathways in cancer research. Mini Rev Med Chem. (2012) 12:120-6. doi: 10.2174/138955712798995011

103. Lin K. Cancer chemoprevention by tea polyphenols through modulating signal transduction pathways. Arch Pharm Res. (2002) 25:561-71. doi: 10.1007/BF02976924
104. Shih RH, Wang CY, Yang CM. NF-kappaB signaling pathways in neurological inflammation: a mini review. Front Mol Neurosci. (2015) 8:77. doi: 10.3389/fnmol.2015.00077

105. Li ZG, Wang XY, Chang JL, Xie WB, Liu TF, Zhang QL, et al. The establishment of supramolecular immunobead real-time PCR and the identification of Cox-2 as a metastasis-related marker in colorectal carcinoma. Oncol Rep. (2012) 28:977-84.

106. Zhao S, Wang J, Qin C. Blockade of CXCL12/CXCR4 signaling inhibits intrahepatic Anticancer Rescholangiocarcinoma progression and metastasis via inactivation of canonical Wnt pathway. J Exp Clin Cancer Res. (2014) 33:103. doi: 10.1186/s13046-014-0103-8

107. Aggarwal BB, Kumar A, Bharti AC. Anticancer potential of curcumin: preclinical and clinical studies. Anticancer Res. (2003) 23:363-98.

108. Rodríguez-Ramiro Ramos S, Bravo L, Goya L, Martín MÁ. Procyanidin B2 and a cocoa polyphenolic extract inhibit acrylamideinduced apoptosis in human Caco-2 cells by preventing oxidative stress and activation of JNK pathway. J Nutr Biochem. (2011) 22:1186-94. doi: 10.1016/j.jnutbio.2010.10.005

109. Venancio VP, Cipriano PA, Kim H, Antunes LM, Talcott ST, MertensTalcott SU. Cocoplum (Chrysobalanus icaco L.) anthocyanins exert antiinflammatory activity in human colon cancer and non-malignant colon cells. Food Funct. (2017) 8:307-14. doi: 10.1039/C6FO01498D

110. Wu X, Li MX, Xiao ZG, Daglia M, Dragan S, Delmas D, et al. Dietary polyphenols for managing cancers: what have we ignored? Trends Food Sci Technol. (2020) 101:150-64. doi: 10.1016/j.tifs.2020. 05.017

111. Tabrez S, Jabir NR, Adhami VM, Khan MI, Moulay M, Kamal MA, et al. Nanoencapsulated dietary polyphenols for cancer prevention and treatment: successes and challenges. Nanomedicine. (2020) 15:114762. doi: 10.2217/nnm-2019-0398

112. María Belén Mariela G, Beatriz L, Laura S, Marianela S, Susana Z, Gabriela Egly F, et al. Argentinean propolis from Zuccagnia punctata Cav. (Caesalpinieae) exudates: phytochemical characterization and antifungal activity. J Agric Food Chem. (2010) 58:194-201. doi: 10.1021/jf90 $2991 \mathrm{t}$

113. Kirsten G, Andreas $\mathrm{H}$, Wali $\mathrm{H}$, Andrea D, Joachim $\mathrm{K}$ Oligomeric proanthocyanidins from Rumex acetosa L. inhibit the attachment of herpes simplex virus type-1. Antiviral Res. (2011) 89:9-18. doi: 10.1016/j.antiviral.2010.10.007

114. Haenen GR, Paquay JB, Korthouwer RE, Bast A. Peroxynitrite scavenging by flavonoids. Biochem Biophys Res Commun. (1997) 236:591-3. doi: 10.1006/bbrc.1997.7016

Conflict of Interest: XHe was employed by the company Changsha Green Leaf Biotechnology Co., Ltd.

The remaining authors declare that the research was conducted in the absence of any commercial or financial relationships that could be construed as a potential conflict of interest.

Copyright (C) 2021 Long, Guan, Hu, Yang, He, Lin, Luo, Li, He, Du and Li. This is an open-access article distributed under the terms of the Creative Commons Attribution License (CC BY). The use, distribution or reproduction in other forums is permitted, provided the original author(s) and the copyright owner(s) are credited and that the original publication in this journal is cited, in accordance with accepted academic practice. No use, distribution or reproduction is permitted which does not comply with these terms. 